\title{
Future Teachers Training For Innovative Activity in Higher Education Institution
}

\section{Zhumahan Myrhalykov}

Professor, M. Auezov South Kazakhstan State University, koncel@ukgu.kz

\section{Asma Kalybekova}

Professor, M. Auezov South Kazakhstan State University, kalubekov@list.ru

\section{Kanat Baibolov}

Associated professor, M. Auezov South Kazakhstan State University, kanat-baibolov@mail.ru

\author{
Doi:10.5901/mjss.2015.v6n6s4p436
}

\section{Abstract}

This article describes the urgent need at present for flexibly thinking and non-standard acting educators, the formation of which is a holistic, multi-structural process aimed at formation of profound professional knowledge, skills and habits , mastery of modern IT, corresponding qualification standards. Kazakh society demands from young teachers not only a wide range of professional and pedagogical knowledge, the ability to work in small and large study groups and to communicate actively with colleagues and parents of their students, but also a whole number of other abilities designed to provide the efficiency of education and upbringing of younger generation. They include: humanistic orientation, personal and professional mobility, desire for self-education, self-development and self-improvement, creativity, spiritual maturity, capacity for reflection, social activity and tolerance, need to study their own activity, need for innovation, etc., which are both the characteristics of a new type teacher and her/his value system. The specificity of various subjects, studied in a pedagogical HEl, requires a more detailed and specific design of the issue of the realization of professional -pedagogical orientation of academic disciplines, taking into account their special features. Not accidentally, V.A. Slastenin among issues, which require top- priority development in context of such fundamental problem of theory and practice of higher pedagogical education, mentions the problem of formation of socially active personality of a teacher, points out professional -pedagogical orientation of training.

Keywords: preparation, future teachers, innovative activity, higher education institution.

\section{Introduction}

Modern Kazakhstani education system is in the stage of dynamic updating, where the process of reforming society in whole on one hand and the logic of the development of the educational system itself on the other hand have served as an impulse (Hmel, 1998).

The current situation in teacher education poses a number of new problems related to the implementation of professional work in difficult conditions of rethinking and modernization of traditional forms and methods of educational process (Lazarev, 2010).

It is necessary to shift from activity, in which the teacher performs an instrumental role, to innovative activity, purposing the object to form teacher's creative personality, ready to work in the renewed and revitalized school, able to design, develop and use innovative projects (Morozov et el, 1991).

A legally enforceable right to freedom of pedagogical creativity contributed to establishment of innovative schools in large numbers, introduction into teaching process of new technologies, there are activities of problem-research creative character to replace teacher's traditional performing activities. Today, the majority of educational institutions operate in the mode of innovation.

Innovative activity is associated with readiness of teacher to develop and implement pedagogical innovations in the educational process. However, the lack of teachers' readiness to adopt and implement practical innovation significantly reduces the impact of the innovations introduced in the educational process (Rubtsov, 2010). 


\subsection{Objectives of the study}

In this regards, we determined the objectives of the study as following:

- to analyze the problem state of future teachers training for innovative activity in higher education institution;

- to construct a model of the new formation teacher ready for innovative activity;

- $\quad$ to reveal the pedagogical conditions of future teachers' professional training for innovative activity;

- $\quad$ to determine the structure of innovative activity;

- $\quad$ to reveal the content of the structural components of students' readiness for innovative activity;

- $\quad$ to reveal the criteria and levels of students' readiness for innovative activity;

- $\quad$ to conduct the experimental work forming future teachers' readiness for innovative technologies use.

\section{The Problem State Analysis}

\subsection{Definition of Innovation}

The concept "innovation" first appeared in studies of cultural studies in the 19th century, and it meant the introduction of some elements from one culture to another one. The science of innovation emerged as a reflection of heightened needs of companies in the development and introduction of new services and ideas (Masyrova, 2003). Initially, the subject of innovation study is economic and social laws of the creation and dissemination of scientific and technological innovations. But very quickly the interests of a new industry expanded and began to include social innovations, and above all, innovation in organizations and enterprises. Innovation was formed as an interdisciplinary field of research at the intersection of philosophy, psychology, sociology, management theory, economics and culture. By the 1870s the science of innovation has become complicated, extensive industry (Belozertsev, 1992).

Pedagogical innovation processes were the subject of a special study of scientists around since the late 1950s in the West and in the last decade in our country. Development of pedagogical innovation in our country is connected with the massive socio-pedagogical movement, with the emergence of contradictions between the needs for rapid development of the school and the inability of teachers to implement it. Mass character of the new is increased. In this regard, it intensified need for new knowledge in understanding the new concepts of "innovation", "new", "innovation", "innovation process", etc. (Lazarev et el, 1999).

The word "innovation" is of Latin origin. In translation it means - update, change, enter of something new, introduction of novelty.

The concept "innovation" is defined as innovation as process of introducing innovation into practice.

Updating practice of general education imposes new demands for teachers and educators' quality. Teacher education is increasingly coming under the influence of the forces that dictate the need for its rapid development. Teachers for the educational systems of the future must be trained today, because before the pedagogical universities there are tasks which have not solved before.

Teacher's readiness to introduce innovations in the learning process is largely determined by the base, which is laid in the period of his university studies. Therefore, in order to be effective, the system of teacher training should also be changed, in accordance with the trends that determine the development of general education practice.

Since the beginning of the 1990s in teacher education innovation processes are significantly intensified. The idea of personality-oriented education gets an increasing recognition. Because of this the goals of teacher education are reconsidered, which are reflected in the state educational standards. Part of the pedagogical universities moved to a multi-level system of teacher training. In pedagogical universities there are increasingly used active learning methods, such as discussions, role plays, case studies, conferences, seminars, debates and others. There is a search for new organization forms and technologies of introducing students in research and practice. Forms and methods of learning results control are modified.

\subsection{Scientists' works covered the problem}

Problems of teacher training in the traditional education system are adequately covered in O.A. Abdullina, S.I. Arhangelsky, E.P. Belozertsev, T.A. llina, I.A. Kolesnikova, N.V. Kuzmina, K.K. Platonov, N.D. Hmel, Sh.T. Taubaeva's works, there is discussed the process of professional qualities formation of the future teacher's personality, his knowledge and professional teaching skills, focus on the teaching profession.

There are developed new technologies of high school training (E.S. Zair-Bek, E.I. Kazakova, B.A. Abdykarimov, 
M.N. Sarybekov, S.T. Kargin), there is studied a problem of students training to develop their own position towards to the pedagogical innovations (M.V. Klarin), innovative type of teacher training (I.A. Protasova, Z.R. Safina, G.T. Musabekova) there are analyzed innovative approaches to teacher education (K. Angelovsky, L.N. Lesohina, E.V. Bondarevskaya, R.R. Masyrova, K.Zh. Azhibekov).

Environment impact on human development was seen in the works of the foreign pedagogy classics - C.A. Helvetius, J.A. Komensky, R. Owen, J.J. Rousseau et al., and in the works of such local teachers and statesmen as P.F. Kapterev, O.B. Krupenina, L.N. Tolstoy, V.P. Shulgin and others. Great attention to the issues development of the educational process environment and relationship was paid in Soviet pedagogy by N.N. Jordansky, N. Krupskaya, A.V. Lunacharsky, S.S. Molozhavy, A.P. Pinkevich, S.T. Shacky, et al., as well as in later works by E.A. Arkin, G.S. Kostiuk, O.P. Okolelova.

The specificity of the educational environment and various aspects of environment issues are reflected in the works of D.B. Belyaev, V.S. Bibler, V.G. Bocharova, Z.A. Galaguzova, N.B. Krylova, T.N. Malkovskaya, Y.S. Manuylov, L.I. Novikova, V.A. Petrovsky, V.D. Semenov, M.M. Skatkin, B.C. Shakurov, A.A. Beysenbaeva, G.Zh. Menlibekova.

Today there is more and more awareness of the need for specialists of a new type, capable of self-realization and operation of the new socio-economic conditions. Characteristics such as professional competence, high level of education, culture determines the future development of the personality in high school, sets a goal of specialist's personality formation with a high level of professionalism, creativity and a high level of pedagogical culture (Romanov, 2011).

The urgency of solving the problem of the university students - future teachers training is due to the integration and modernization processes taking place in modern society and education; to the deepening conflict between the requirements for the modern person's personality and activity in the form of society order, and the actual level of pedagogical universities graduates' pedagogical culture.

\subsection{Approaches for innovative activity}

The main purpose of professional teacher education is to teach students to solve creative pedagogical tasks. The process of the future teacher's professional formation should probably model the structure of the innovative activity. The basis of constructing the concept of teacher training for innovative activity was laid by system, reflective-active and individually-creative approaches providing construction and operation of the whole process of the teacher's personality formation (Stepanov et el, 2005).

Due to the system approach all parts of teacher education should stimulate the expression of all the components of innovative activity in their unity.

Realization of the reflexive-activity approach involves the development of teacher's ability to enter into active research position in relation to its activities and to itself as its subject for the purpose of critical analysis, interpretation and evaluation of its effectiveness for the student's personality development.

The individually-creative approach displays the personal level, ensuring the identification and formation of teacher's creative individuality, the development of his innovative mind and unique technology activities.

Teachers today have to train for the organizing educational systems of the future. The teacher's readiness to introduce innovations in the learning process is largely determined by the base, which is laid in the period of his university studies (Slastenin et el, 1997).

\section{A Model of New Formation Teacher}

Teacher of the new formation is the spiritually developed creative personality, capable for reflection, professional skills, teaching gift and craving for pioneering. Ideally, the teacher should clearly understand the intrinsic value of education, be a culture person, know his subject, pedagogy and psychology perfectly, use student-centered teaching methods and have the motivation to further growth and development of his personality.

In this regard, the proposed model of the teacher of new formation imposes on his personality the following requirements:

1) professional orientation of the person;

2) competence of the teacher's personality;

3) ideological and moral position of the person;

4) innovation and creativity of the person;

5) adaptation of the teacher to the profession conditions. 


\subsection{Components of the Model}

In this article we would like to elaborate on one of the requirements for teacher's personality - professional orientation, which is basically opened by three components - conceptual, procedural and personal.

Conceptual components of the educational process professional orientation consider and examine the contents and structure of the acquired knowledge and skills of the future teacher in the process of training.

Procedural components of the person's professional orientation consider and study ways of self-regulation and use of acquired knowledge for formation (Berikhanova, 2003).

Personal components view and study issues of personality formation, involving the fundamental knowledge and competency, creativity, adaptability, mobility and communicability of the future specialist.

From the above components of a professional orientation of the future teachers training the most important and fundamental is the education content.

\subsection{Content of Teacher Education}

As is known, the content of teacher education is a moving phenomenon; it reflects the fundamental concepts of modern science and meets the needs of school practice. That is why at the moment it is significant to change in content of the future teacher training. It is necessary to link technology training to the demands of life. The content of training should include study by students of the basics of natural, psycho and pedagogical, technical and technological, organizational, economic, special and methodical knowledge, skills and abilities. All this requires to "arm" future teacher with the interdisciplinary integration content, necessary for him to work in the modern school.

Therefore, for effective system of the future teacher training, it must also be changed, in accordance with the trends that determine development of general education practice. The effectiveness of solving these problems is greatly facilitated by the introduction in the educational process of the university of innovative educational technologies, active learning methods (Kalybekova, 2005).

Pedagogical university students training for innovations in teaching activities should be carried out mainly through formation of readiness to perception, development of scientific research; transfer of other teachers' innovative experiences, and his adaptation to the new conditions; development of their own innovations (methods, forms, technology of teaching and education); transfer of own innovative experience; organizing and conducting experiments; maintaining a favorable climate for innovative pedagogical community (Kalybekova, 2007). The determining factor of the future teacher's readiness to innovative activity is features of this activity and conditions of its occurrence. Therefore, the content of readiness component is determined by the characteristics of innovative educational activities. Future teachers' readiness to the innovative activity is generated in the process of integrating innovation in search, in experimental work, which provides an optimal environment for continuous creative comprehension of reality and leads to the establishment, development and improvement of their skills and professionalism (Kalybekova, 2009) .

\subsection{Pedagogical Conditions}

Therefore, there is a need for pedagogical conditions of pedagogical university students' professional training as the subjects of innovation. This work can only be successful if there are followed the pedagogical conditions:

- Innovative trends in education must be adequately reflected in the objectives, content, methods and organizational forms of teacher training;

- A model of pedagogical university graduate with a clear definition of the innovative activity components is developed;

- Conditions for a continuous pedagogical internship undergoing in innovative educational institutions are created.

Future teachers training for innovative activity is effective, if there is determined the content of teaching internship, suggesting the targeted programs of research problems and practical tasks for the study of innovation processes in educational institutions.

In traditional education a goal is set through curriculum content and evaluation criteria of their level of development. The teacher in the traditional training model serves mainly as a "lesson giver." In this model, the training is reproductive in nature, since the content of education is transferred to the finished form.

Innovative technologies of training impose other requirements for teachers and are based on the students' active emotive communication with each other and with the teacher. Describing the modern educational process, the 
researchers emphasize that the crisis phenomena, most pronounced in the last decade, among other things, are a consequence of its lack by the dynamics of science, industry and society.

\subsection{Indicator of Pedagogical Innovations}

The main indicator of pedagogical innovations is the presence of a progressive start.

Innovative pedagogical activity is a process of creation and development of pedagogical innovations.

V.S. Lorensov, M.M. Potashnik, O.G. Homeriki classify innovative pedagogical activity according to a number of parameters:

1. On the basis of correlation with one or another part of the educational process.

2. On the basis of the scale (volume) of changes.

3. On the basis of the innovative potential of activity.

On the basis of the relationship to the predecessor.

In Angelovsky's works, summarizing of US scientists' researches (Rogers, Myles), France (Brainsuik, Bohlen), England (Nayhof, Marklund), Yugoslavia (N. Potkonjak, P.Mandich) there is a classification of innovative educational activities based on the following criteria:

1. Due to the sphere of distribution.

2. Due to implementation way of the new.

3. Due to the breadth and depth of innovative activities.

4. Due to the pioneer nature (Angelovsky, 1991).

\subsection{Structure of Innovative Activity}

In the structure of innovative pedagogical activity contains the following components: motivational-valuable, conceptual, procedural.

Motivational-valuable component determines teachers' attitude to innovative activity implementation, affects the learning process. Conceptual and procedural are also interrelated and interdependent: the first is a prerequisite for the formation of the second one, and procedural component, in its turn, actualizes the need for new knowledge and affects the motivational component.

Combination of knowledge with experience is related to the major conditions of the person formation as a subject of activity, continuous improvement of his skill in a particular area of activity.

Revealing and basing of pedagogical conditions which provide the future teacher professional training as the subject of innovative activity, require the following tasks:

1. Revealing the contents of the structural components of readiness for innovative activity.

2. Revealing the criteria and levels of the readiness.

One of the important factors of the innovative activity is the teacher's creativity, which is necessary to create new curricula, textbooks, as well as to modify this new level of implementation. Action of creative component of readiness to innovate is reflected in the original solution of pedagogical problems, in improvisation and impromptu, in both momentary art and training.

\subsection{System of Professional Training}

The teacher training as subject of innovative activity is a specific part of future teachers' professional development. It is under the influence of general objective and subjective conditions. The objective conditions independent of consciousness of educational system objects and determining the professional formation of pedagogical university students as a whole and as subjects of innovative activity in particular, are associated with a real system of pedagogical university students' professional training. These include:

- Professional-pedagogical orientation of training;

- The content of the educational process;

- Unity and interrelation of educational and practical aspects of the training.

Subjective conditions affecting the future teachers' professional development are personal preconditions of professional-pedagogical activity mastering.

The subjective conditions include:

- Intellectual abilities; 
- Pedagogical abilities and skills;

- Professional-pedagogical orientation of the person;

- Own activity in mastering future profession.

For the purpose of diagnosing readiness formation of motivational component to pedagogical university students' innovative activity the study was conducted. There were divided into two groups: control and experimental. Studied groups were asked to answer the questions of the developed two questionnaires aimed, on the one hand, to identify their knowledge of innovation, and on the other hand, to determine the susceptibility to innovation.

\section{Results}

The results of the pilot study showed that the majority of future teachers are planning to use the innovative methods and forms. Especially it is typical for the control group. It can be concluded that the majority of future teachers had antiinnovation barriers to the innovation development. Anti-innovation barrier is a concept traditionally used in sociological and psychological literature. Barriers are usually caused by both individual characteristics of teachers and socialpsychological characteristics of the community where he is.

In general, the level of the experiment participants' knowledge in the field of pedagogical innovations was low, existing knowledge of both groups studied was not enough for the effective development of innovation, the success of the professional and research activities.

For the purpose of diagnosing the development degree of creative activity, creativity, determining susceptibility, open problems, we used a set of techniques to determine the sensitivity to problems. The level of sensitivity to the problems is evaluated by the situations in which future teacher's creative personality can be revealed.

Studying the process of pedagogical university students' professional training as the subjects of innovative activity is essential to improve the quality of future teacher training, especially in connection with the intensification of innovative processes in the modern education system.

Effective achievement of the goal and objectives of training the future teacher for innovative activity in practice has its own specific character in each individually taken institution and requires a carefully thought-out and well-coordinated work of all subjects of the educational process of the Higher Education Institution. In M.Auezov South Kazakhstan State University the leading strategic goal is to develop and implement an effectively acting model of innovative education and full-fledged development of professionalism and personal qualities of the future teachers. In this context, the main effort of Training-Methodological Department of the Higher Education Institution is aimed at the system introduction of new educational technology of training and making the educational process to be innovative and creative. The conducted events have contributed significantly to the improvement of training activity and achievement of goals in the area of quality management system.

\subsection{The tasks of innovative development}

The tasks of innovative development of the educational environment of the Higher Education Institution are realized by implementing the following set of pedagogical technologies:

- distance learning technology;

- information technologies;

- technology of case studies;

- technology of portfolio;

- technology of development of critical thinking;

- virtual laboratories;

- developing training technology;

- role-play technologies;

- technology of problem and contextual training.

\section{Discussion}

Analysis of the activity of the faculties of the University showed that the most frequently used innovative technologies in professional training of future specialists are: information technologies (83\%), technologies of developing training (83\%), technology of case studies (77\%), design technologies (56\%), technology of critical thinking development (43\%).

The improvement of the content and methods of teaching the cycle of pedagogical subjects is of paramount 
importance. In their teaching and educational activities the teachers of the chair of general pedagogics and ethnopedagogics of M.Auezov SKSU are oriented on the development of promising new developments of pedagogical theory and practice, for which the variability of technologies, activating students' cognitive activity, is a characteristic feature. At this additional literature, up-to-date sources of information, audio-visual facilities are used as an organizational component. Simultaneously individualization of the educational process with the use of information technologies' capabilities is used.

Considerable potential is in the use of role-play technologies in the educational process of higher school. In particular, in the course of teaching the disciplines "Pedagogics", "Teaching mastery" the role-playing game "Portfolio of a modern teacher" has been successfully used. During the game, students - the future teachers - try on a kind of the image of an "ideal teacher". An interesting point of the game is that due to the individual perception of each student this image has specific properties and qualities, on the basis of interchange of which it is corrected and updated (Kalybekova, 2011).

Particular attention in the process of preparation for the training sessions the teachers of the chair of general pedagogics and ethno-pedagogics pay to the problem-based technology of teaching, the use of which allows to prepare students - the future teachers - to the solution of problems of organization of interaction with the subjects of the educational process (junior school children, teenagers, high school students, parents, colleagues, administration). At sessions dedicated to the organization of interaction with children of different ages, ideas about the active subject role of the child in the pedagogical process, orientation of the teacher to promote the development of the child, participation, cooperation, co-creation with the child, search for and creation of different options to address these pedagogical situations are developed. Problems of interaction with parents and colleagues are considered in the context of search of like-minded persons and assistants in terms of organizing a student-centered pedagogical process. For practical training the students in micro-groups prepare innovative developments, models, projects aimed at solving specific pedagogical problems, taking into account age and personal characteristics of the subjects of interaction. Developing innovative technologies, methods and techniques of teaching activity, students not only immersed in the problems of interaction, but also they learn to work as a team, to search jointly for a creative solution of the problem, to coordinate their positions. When creating innovative projects, students orient not only on the use of already existing forms of cooperation, but also to adapt these forms to topical current problems. Students are encouraged to go beyond one form and to develop a system of forms of interaction, to determine the conditions of an organizing project, to predict the expected results of the implementation of the innovative project, allowing to judge about the personal transformations of the subjects of interaction.

\subsection{Use of innovative methods}

The problem of tools selection of content transmission of pedagogical education is more complicated. Study of theoretical material and practical experience of innovative activity of high school faculty led to the conclusion that the basis of future teachers preparation must rest upon activity, based on mastery of scientific idea of the world and pedagogical reality, on cultural analysis and synthesis, upon approval of educational values and goals. This is possible at modeling and formation of new ideals, goals, values on the basis of modern educational technologies.

Use of interactive methods, business and subject-role games, case-based technology, creation of problem situations allow to solve successfully a whole range of problems of professional-pedagogical training of future teachers in Higher Education Institution. This set of teaching techniques and methods can be successfully used in "acting out" fragments of educational events, unconventional lessons, sessions with the use of elements of innovative educational technologies, parent-teacher meetings. It is advisably to carry out this kind of business games during seminars in disciplines: "General Pedagogics", "Introduction into the profession", "Didactics", "Theory of Education", "Methods of teaching pedagogical disciplines", "Methods of educational work", "Ethnopedagogics" (Kalybekova, 2011).

Of particular importance is the use of pedagogical innovations in teaching the discipline "Ethnopedagogics." This is a relatively new academic discipline and many elements in the methodology of its teaching, taking into account the growing interest in folk traditions in modern conditions, of course, need to be improved. In order to solve optimally the problem of professional and pedagogical training of students, the staff of the chair of general pedagogics and ethnopedagogics actively uses the pedagogical situations of communicative nature, the solution of which is made by the students with the use of traditional pedagogy. "Playing" fragments of lessons, based on ethnopedagogical technologies, according to which the future teachers design the organization of the teaching-educational process at school on the basis of elements of folk pedagogy, is an innovative form of training sessions. Also during the seminars the theatrical performances of ceremonies, that reveal the essence and true teaching-educational potential of folk traditions, acquire a 
great importance. The participation in various types of ritual activity of the Kazakhs and other peoples, living in the Republic of Kazakhstan, is already a peculiar kind of example of the folk drama: each participant of the ceremony has her/his role, image, function, traditions and folk etiquette that regulate the sequence of actions and features of their relationships. Special flavor and originality are emphasized by national clothes, items of folk life, music and song-poetic accompaniment, creating an ideal picture for holding the ceremony. The rich palette of positive emotions, the festive atmosphere that accompany many elements of the traditional ceremonial activities are very important. Therefore, in the present conditions, when the tasks of renaissance of folk traditions are paid great attention, the future teachers must not only know the essence and the true conceptual meaning of the features of national system of education, but also be able to use them actively. In this regard, the inclusion of innovative technologies into the process of teaching the discipline "Ethnopedagogics" enables not only to extend the students' knowledge in the field of folk culture, but also forms a special model of pedagogical activity, in which innovative techniques and specific ways of organizing pedagogical interaction, borrowed from folk pedagogy, combine organically, mutually enriching and complementing each other.

As a result of comprehensive measures students' progress improves, a sufficient basis for the application of innovations in the upcoming academic work is being formed, they face a creative level of mastery of the profession, participate in conferences of National and International level.

Innovative technologies cover all components of the teaching-educational process of the university: lectures, practical and seminar classes are applied in the process of pedagogical practice of the students. To realize this the University has the necessary logistical, teaching-methodological and human resources support. The university has 46 computer labs in 9 educational buildings and 5 in students' dormitories. All class rooms are equipped with computers Pentium IV and Pentium-D.

The university widely uses the diagnostic method of monitoring the quality of education: learning outcomes of each student are assessed on the basis of her/his real educational opportunities and the initial level of knowledge. The most promising assessment system is the rating of the student's knowledge. The data of this diagnostics are used for further adjustment of the learning activities. An automated system of computer testing successfully operates in the Higher Education Institution. This system works according to http-hypertext transfer protocol that allows to test not only in the local network, but also through Internet, and it is the basis of the distance learning system. The authorized and anonymous testing modes are introduced. The system communicates with the AIS on the level of the data that ensures its full integration into the information system and use of data, obtained in testing, for automated calculation of final grades. An extensive database of test tasks in disciplines, which contains more than 14 thousand tasks, has been created in SKSU. Its further development is planned for the knowledge testing with open tasks. Subprogram (macros) and instructional guidelines for semi-automatic mode of preparation of test tasks have been developed. Macros and instructional guidelines are posted on the website of the university.

\subsection{Use of network}

The corporate information-educational university network at the speed of Internet access $1024 \mathrm{kbps}$ with the volume of information received unlimited effectively functions at SKSU. The logical structure of the information system of the University is a set of functionally oriented subsystems, including the following elements:

- $\quad$ automated information system ISVUZ;

- $\quad$ automated library system EIC;

- information systems of departments, including WWW-servers, database servers, Proxy servers and mail servers of the university;

- $\quad$ web-site of SKSU (www.ukgu.kz); automated information educational system "www.ckt.ukgu.kz;

- automated information-educational complex "Electronic University" of the Institute of Distance Learning of SKSU "Prometheus" (www.sdo.ukgu.kz);

- telecommunication center for the teaching-educational process;

- automated information system of teaching process management.

The control system of management ACS with subsystems: "Library" (automated catalogs), "Dean's office" (students' number, personal data, current and final performance, rating, transcript), "Educational department" (calculation of hours, students'number, teaching staff, schedule, session), "Distance Learning", "Monitoring the quality of the learning process", "Quality Management System" is introduced into the learning process. Every year ACS is reinforced with new subsystems and functions.

In the Educational Information Centre (EIC) of M.Auezov SKSU bibliographic databases of own generation were created: "Publications of SKSU scientists"; "Theses, defended in SKSU"; "Books"; "Articles"; "Subscription"; "Periodicals"; 
"Rare books"; "Electronic Fund". The use of electronic communications is aimed at creating conditions for self directed work of students. For this purpose an electronic resource center (ERS) has been opened. The created ERS is a multitype information-technological complex that operates on the basis of using modern Internet technologies, electronic delivery of materials, support of the mode of interactive videoconference. The functionalities of the center are multivarious. Extensive work in transfer of educational, scientific literature on electronic media is being carried out. Electronic forms of service, aimed at creating conditions for self directed work of students, operate.

\section{Conclusion}

Effective solution of the above mentioned goals and objectives in practice has its specificity in each individual educational institution and requires carefully thought-out and well-coordinated work of all subjects of the educational process of the university. In M. Auezov South Kazakhstan State University development and implementation of an effective model of innovative education and full development of professionalism and personal qualities of future teachers is the leading strategic goal. Thereupon the main effort of Educational -Methodical Department of the HEl is aimed at system- based introduction of new educational technologies of training and making the educational process be innovative and creative. The conducted events have contributed to the improvement of training activity and achievement of goals in quality management system area.

Analysis of the University faculty activity showed that the most frequently used innovative technologies in training the future specialists are: IT (83\%), technologies of developing training (83\%), technology of case studies (77\%), design technologies (56\%), technology of critical thinking development through reading and writing (43\%).

The paper discusses in more details some innovative technologies used in M. Auezov South Kazakhstan State University, the application of which allows to optimize the process of professional-pedagogical training of future teachers in HEl .

Thus, the professional qualities of future teachers are being formed and they manifest in the activity through the systematic solution of various problems, arising in the process of professional pedagogical training in higher educational institution.

\section{References}

Angelovsky, K. (1991). Teachers and innovation. Moscow: Education.

Belozertsev, E.P. (1992). Teacher Education: Reality and Prospects. Pedagogy, 1 (2), 61 - 66.

Berikhanova, S.A. (2003). About pedagogical conditions of formation of future teachers' readiness to use modern pedagogical technologies. Bulletin Journal of Higher School in Kazakhstan, 3, 51-55.

Kalybekova, A.A. (2011) The use of innovative technologies in teaching pedagogic subjects in high schools. Scientific pedagogical journal "Bulletin of Scientific Humanitarian Education», 1 (3), 24-26. Moscow.

Kalybekova, A.A. (2011). Kazakh folk wisdom about education. Almaty: BAUR.

Kalybekova, A.A. (2009) Practice of realization of innovative technologies at university. Proceeding of International Cooperation «Lifelong education for sustainable development» (pp. 426-430). Saint-Petersburg.

Kalybekova, A.A. (2005) Psychological fundamentals of formation and development of valeogonative strategies of a person in the context of health creative activities. Proceedings of the XII European Conference on Developmental Psychology (pp. 142-148). University of La Laguna.

Kalybekova, A.A. (2007) Theoretical and Applied Fundamentals of Kazakh Folk Pedagogy. Almaty: BAUR.

Lazarev, V.S. (2010). Program-oriented approach to the introduction of the new standard. Problems of modern education, 3, 27-29.

Lazarev, V.S., Honoplina, N.V. (1999). Scientific report. Pedagogy, 6, 12-18.

Masyrova, R.R. (2003). Innovative educational technology. Management in education, 2, 54-59.

Morozov, E.P., Pidkasisty, P.I. (1991). Training of teachers to innovative activity. Soviet pedagogy, 10, 88-93.

Romanov, K.E. (2011). Designing educational environment: textbook. Shuya: GOU VPO «SHGPU".

Rubtsov, V.V. (2010). Psycho-pedagogical teacher training for the "New School". Problems of modern education, 1, 15-17.

Slastenin, V.A., Podymova, L.S. (1997). Pedagogy: innovative activity. Moscow: Master.

Stepanov, E.N., Luzin, L.M. (2005). For the teacher about modern approaches and concepts of education. Moscow: Sphere 